\title{
Using $T$ cell lymphokines to enhance the immune response against Newcastle disease in vaccinated broiler chickens fed naturally contaminated diet with different mycotoxins
}

\author{
B.H. Saud ${ }^{1}$ and M.T. AL-Zuhariy ${ }^{2 *}$ \\ ${ }^{1}$ Department of Pathology and Poultry Diseases, College of Veterinary Medicine, ${ }^{2}$ Department of Pathology and Poultry \\ Diseases, College of Veterinary Medicine University of Baghdad, Baghdad, Iraq, *Email: dmshtak27@gmail.com
}

(Received July 26, 2019; Accepted September 09, 2019; Available online July 27, 2020)

\begin{abstract}
The current study aimed to reduce the toxic effect of different mycotoxins and enhance the immunity against ND virus in broiler chickens by using lymphokines from hyperimmunized birds with Salmonella typhymurium. The study included three stages, the first stage included isolating Salmonella typhymurium. The second stage was immunized chicks with Salmonella typhymurium. The final stage of the study was accomplished by treating 250 broiler chicks (divided into 5 groups, 50 chicks /each) with the following treatments; G1: $0.5 \mathrm{ml}$ lymphokines was injected I/P at day one old with live ND vaccine (la Sota strain) after 30 minutes in drinking water, the process repeated after 10 days; G2: the same as in G1 but inactivated killed vaccine was used s/c,no repetition was carried out at 10 days ; G3: a combination of G1 and G2 with revaccination of live La Sota vaccines only at 10 days; G4 : only vaccinated with live La Sota vaccine repeated at 10 days; G5: no treatments (negative control). All groups were challenge with local isolate of NDV $\left(100 \mathrm{ELD}_{50} 10^{5}\right)$ at 25 days, all groups except the fifth group were fed on contaminated diet with mycotoxin. The results of the present study showed a significant increase $(\mathrm{P}<0.05)$ in antibodies titre against ND in the third group, followed by the first and second groups Measured by ELISA and hemagglutination (HI) test, A significant decrease $(\mathrm{P}>0.05)$ in the oxidation status $\left(\mathrm{H}_{2} \mathrm{O}_{2}, \mathrm{MDA}\right.$ and $\left.\mathrm{LPO}\right)$ and significant increase in the antioxidant defense (GSH-PX) in the liver and spleen samples. We conclude from the current study that the Salmonella immune lymphokines (SIL) helps in enhancement the level of immunity against Newcastle disease and $\mathrm{n}$ reduction the side effects of which mycotoxin.
\end{abstract}

Key words: ND, SIL, Mycotoxin, T cell, ELSA, HI

DOI: 10.33899/ijvs.2019.125977.1204, ( ) 2020, College of Veterinary Medicine, University of Mosul.

This is an open access article under the CC BY 4.0 license (http://creativecommons.org/licenses/by/4.0/).

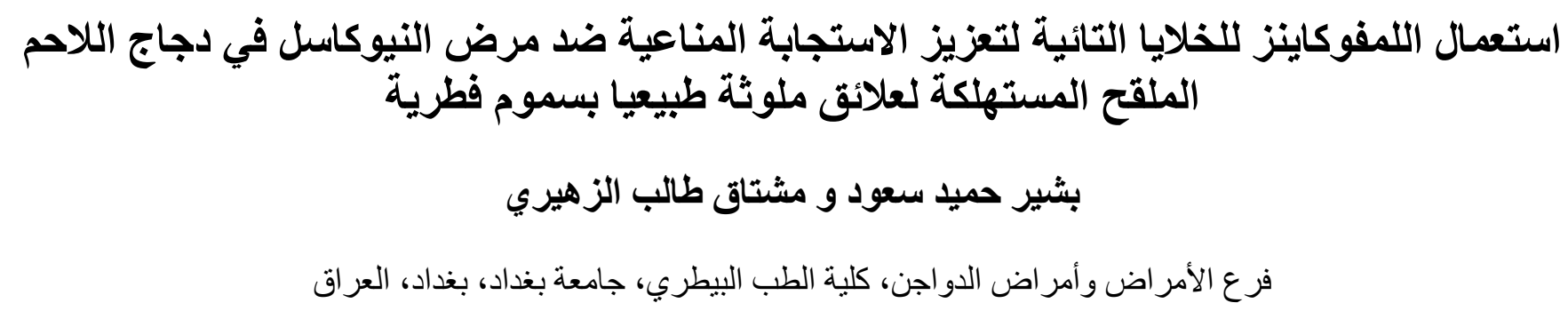

هدفت الدراسة الحالية الى تقليل التأثير ات السمية للسموم الفطرية وتعزيز المناعة ضد مرض النئ النيوكاسل في الدجاج اللاحم باستخدام

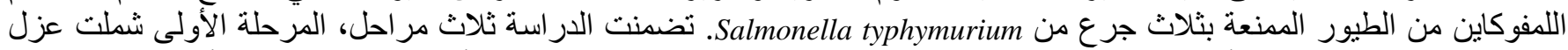

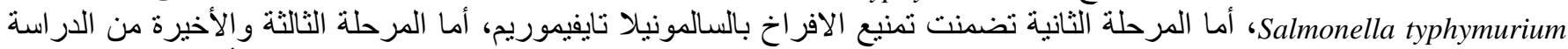

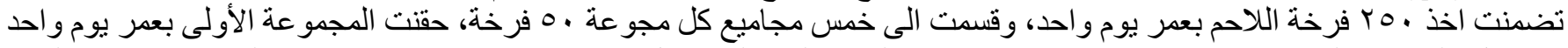
0, • مل بالتجويف البرينوني Lymphokines وبعد · r دقيقة لقحت بلقاح النيوكاسل (La Sota strain) عن طريق ماء الثرب، و واعيدت الحقن 


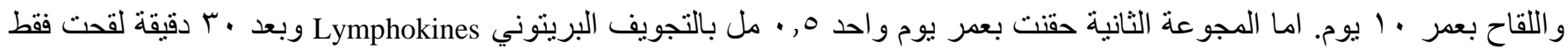

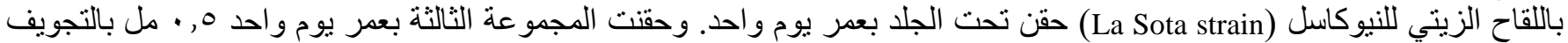

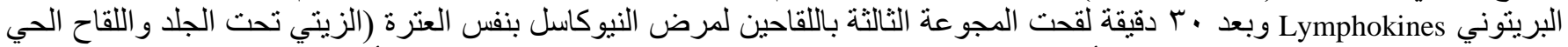

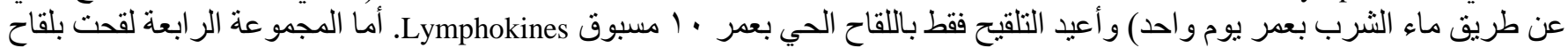

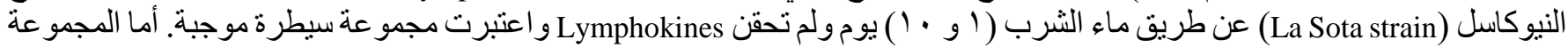

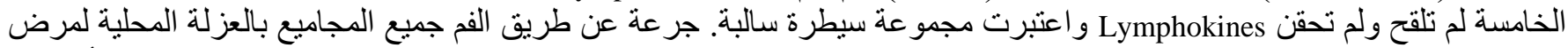

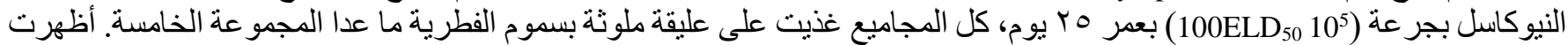

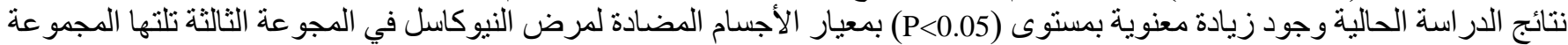

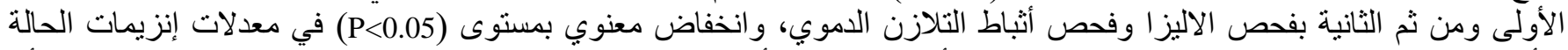

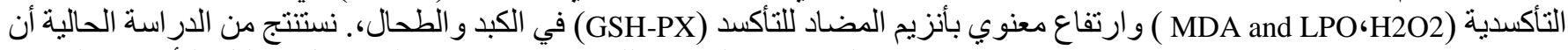

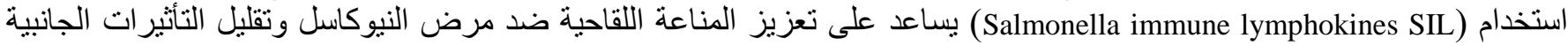

اللسموم الفطرية.

\section{Introduction}

Mycotoxins are diverse group of harmful particles to animal and human, which are the secondary metabolites of different toxigenic molds, especially aspergillus, penicillium and fusarium species, mycotoxins are produced in the grains as well as in the pre- and post-harvest feed in different environmental conditions and due to the large diversity of their toxic effects and their synergistic properties therefore, mycotoxins consider more risky to the consumers of food and contaminated feed (1). The consumption of low concentrations of ycotoxins for long periods exposes cells of the intestinal mucosa to damage, however the intestinal mucosa possesses both natural and specific immune components (2). Bouhet and Oswald (3) the main function of physical barrier of the intestinal mucosa is the transfer the electrical resistance through the epithelial layer, which found in the monolayer cells. Mclaughlin et al. (4) show that mycotoxins damage the proteins found in cell junctions and thus reduce the transmission of electrical impulses which is the transfer of cytokines between immune cells. Metabolic products of innate toxins affect the immune system of the intestinal mucous, which in turn significantly affects the performance and productivity of the animal, because the stimulation of mucous immunity is important in protecting against many of the germs that invade these surfaces and enter the body and cause diseases (5). It is known that oral vaccination is one of the most practical and economical methods in poultry However, the presence of mycotoxins in diet interferes with the immune response by affecting the mucous membranes and thus reduces the level of local immunity resulted after vaccination, making birds vulnerable to infectious and rapidly spreading diseases (6). Newcastle disease is a contagious, endemic and rapidly spreading disease that causes significant economic losses to the poultry industry. The pathogen of this disease is Paramyxovirus, Genus Avulavirus, family Paramyxoviridiae (7). Although many vaccine programs are used to ND control, the disease is endemic in many countries (8). Some research has confirmed that immune response is enhanced by many herbal and vitamins, but immune response is still low due to mycotoxins (9). Rashad and Mushtaq (10) confirmed that the use of lymphokines from Salmonella Typhmurium (Slmonella immune lymphokines SILK), enhanced the immune response against the ND challenge without using the vaccine by stimulating many immune cytokines, which are regulatory proteins produced by some Immune cells in to protect the body against infections. Mushtaq et al. (11) confirm use of SILK in the early days stimulated the immune response to protect the chicks from infectious bronchitis disease after the challenge of local isolation of the disease. Mushtaq, (12) also showed the role of SILk in promoting the maternal immunity at one day-old against avian influenza infection. Therefore, we expect that the addition of SILK to mycotoxins -contaminated diets could reduce the effects of mycotoxin during oxidative reduction and increased antioxidant defense systems with high response against ND.

\section{Materials and methods}

\section{Detection of Mycotoxin in diet}

Mycotoxin was detected using the ELISA test. A 20gram feed sample is mixed with methanol (Fisher, Pittsburgh, PA, USA). Mixed with water (30/70 vlv) and shaking for 3 minutes. Then the mixture filtrated with Whatman filter (Whatman Clifton, NJ, USA), collects the supernatant and determined the concentration of toxins using ELISA kit (Agra Quantum mycotoxin assay, Romer, Singapore). Starter and finisher diet (A1) for (G1, G2, G3 and G4), while starter and finisher diet (B1) for G5 (Table $1)$.

\section{Preparation of lymphokines}

Salmonella typhymurium was isolated from Salmonella typhymurium-infected birds. Salmonella was grown on nutrient broth and peptone water. The dishes were incubated 
at $37^{\circ} \mathrm{C}$ for 24 hours until sedimentation occurred with small white deposits. The bacteria were then planted on selected medium such as MacConkey agar and SS agar. After the growth of bacteria on the growth media and the appearance of black spots, the bacteria were identified biochemically using API20. After determining the type of bacteria Salmonella typhymurium, the bacterial infected dose was determined by injecting of chicks by $1 \times 10^{8} \mathrm{cfu}$. Based on spectrophotometric, the required concentration of the bacteria was determined at a standard level of $625 \mathrm{~nm}$ in length. Two groups of chicks were included, each group included 20-day-old chicks. The first group had three oral doses (ages 7, 14,21). Other group did not give anything and considered as control group. At 35-day, T cell cells collected from spleen of infected birds, after crushing of infected spleens, T- cells were harvested by centrifugation at 1500 rpm. T-cells were then cultivated on RBM dishes with the addition of Co- A for stimulation of lymphokines secretion. Lymphokines were collected by centrifugation of filtrate at $3000 \mathrm{rpm}$ according to (13).

Table 1: Residual of Aflatoxin, Ochratoxin and T2 contamination of feed collected feed mills estimated by ELISA test

\begin{tabular}{lcccc}
\hline \multicolumn{2}{c}{ Groups } & $\begin{array}{c}\text { Aflatoxin } \\
\text { ppb }\end{array}$ & $\begin{array}{c}\text { Ochratoxin } \\
\text { ppb }\end{array}$ & $\begin{array}{c}\text { T2 toxin } \\
\text { ppb }\end{array}$ \\
\hline \multirow{2}{*}{ Starter } & A1 & 46.768 & 3.232 & 25.528 \\
& B1 & 2.565 & 0.323 & 0 \\
\multirow{2}{*}{ Finisher } & A2 & 48.661 & 4.765 & 30.636 \\
& B2 & 1.221 & 0.435 & 0 \\
\hline
\end{tabular}

ppb: part per billion.

\section{Preparation of viral inoculum}

Newcastle disease isolate was taken from the Department of Pathology and Poultry Diseases, college of Veterinary Medicine, University of Baghdad. ELD $\mathrm{E}_{50}$ was identified as $10^{5}$ according to (13), and the sample was kept at deep freezing $(-80)$.

\section{Experimental design}

The experiment was carried out using 250 chickens of one-day broiler, divided into five groups each group 50 chicks, treated as follow: the first group was injected $0.5 \mathrm{ml}$ intraperitoneal with Lymphokines at one day, after 30 minutes vaccinated with Newcastle (ND) vaccine (La Sota strain) through drinking water, the injection and the vaccine was repeated at 10 days. The second group was injected 0.5 $\mathrm{ml}$ intraperitoneal with Lymphokines at one day, after 30 minutes was vaccinated only with killed ND vaccine at 1 day subcutaneously. The third group injected $0.5 \mathrm{ml}$ intraperitoneal with Lymphokines, after 30 minutes the third group vaccinated Newcastle disease with the same strain kill and live vaccine through subcutaneous and drinking water respectively and was vaccinated only with the live vaccine at 10 days preceded by lymphokines. The fourth group was vaccinated with ND vaccine by drinking water at 1 and 10 days with not treated with Lymphokines and considered as positive control group. The fifth group was not vaccinated and not treated with Lymphokines considered as negative control group. All groups were challenge with local isolate of NDV $\left(100 \mathrm{ELD}_{50} 10^{5}\right)$ at 25 days, where is the group which consume mycotoxins only.

\section{Samples}

Blood samples from the jugular vein were collected at different period 1, 7, 14, 21, 28, 35 and 42 to determine the antibody titer against Newcastle disease using ELISA and haemaaglutantination inhibition test after separation of the serum.

\section{Oxidative status and antioxidant defense in liver and spleen}

A total of five tissue samples of liver and spleen were collected from each group at 42 days after 12 hours of fasting. One gram was taken from each sample (liver or spleen), Placed in ice-cold and mixed with saline buffer (1: $9 \mathrm{wt} / \mathrm{v}$ ) then crushed with ultra-turrax (T8, IKALabortechnik, Staufen, Germany). The concentration of the Mixture becomes $0.1 \mathrm{~g} / \mathrm{mL}$ for analysis. The mixture was separated by a centrifuge $(1000 \mathrm{rpm})$ for 10 minutes at a temperature of $4^{\circ} \mathrm{C}$. It is then kept at $-70^{\circ} \mathrm{C}$ until it is used to determine concentrations of (H2O2, MDA, LPO and GSHPX) using the commercial kits (Nanjing Jiancheng Bioengineering Institute, Nanjing, china).

\section{ELISA examination}

For determination the level of titers against ND virus vaccination in birds' protocol was performed according to ProFLOK NDV direct ELISA kit (Synbiotics-USA).

\section{Examination of hemagglutination inhabitation}

Hemagglutination inhabitation is one of the most specific tests for detection of antibodies against Newcastle disease in serum of infected or vaccinated birds the procedure has applied according to (14).

\section{Challenge test}

At 25-day, challenge test was performed using local isolate of Newcastle disease at $\left(100 \mathrm{ELD}_{50} 10^{5}\right)$ according to method of (13). The chicks were monitored for 10 days, and the morbidity and mortality were recorded for each group.

\section{Statistical analysis}

The final results were statistically analyzed using statistical analysis system (SAS). The means were distinguished according to the least significant differences and at a significant level $(\mathrm{P}<0.05)$. 


\section{Results}

\section{Immunity against Newcastle}

Ten chicks were slaughtered before dividing chicks in groups in order to determine ND maternal immunity was accomplished by using ELISA and HI techniques. Titer WERE $7340.9 \pm 202.7$ and $204.8 \pm 22.1$ respectively. The study identified the role of lymphokines in improving the immune response to ND under effect of mycotoxins by giving 30 minute before vaccination. Table 2 shows significant differences at level $(\mathrm{P}<0.05)$ in $\mathrm{Ab}$ titre against ND in all periods. A significant increase at level $(\mathrm{P}<0.05)$ in $\mathrm{Ab}$ in the G3 followed by the (G1 and G2) groups respectively in $(14,21,28,35)$ days compared with G4 which recorded a significant decrease in Ab against ND, while G5 which is resemble the maternal immunity, it was recorded a decrease reached to zero in 14 days and continuous to 35 days. After challenge with local isolate of NDV all groups were recorded significant increase in $\mathrm{Ab}$ at 42 days, but G5 was recorded highly increase in Ab reach to $15792.2 \pm 903.9$.

Table 3 showed HI results of Abs against ND were identical to ELISA results. There were significant differences at level $(\mathrm{P}<0.05)$ in $\mathrm{Ab}$ titre against ND for all periods. There was A significant increase at level $(\mathrm{P}<0.05)$ in $\mathrm{Ab}$ in the $\mathrm{G} 3$ followed by the (G1 and G2) groups respectively in $(14,21,28,35)$ days compared with G4 which recorded a significant decrease in Ab against ND, while G5 which is resemble the maternal immunity, it was recorded a decrease reached to zero in 14 days and continuous to 35 days. After challenge with local isolate of $\mathrm{NDV}$ all groups were recorded significant increase in $\mathrm{Ab}$ at 42 days, but G5 was recorded highly increase in $\mathrm{Ab}$ reach to $415.4 \pm 15.5$.

\section{The oxidative status and antioxidant defense}

Table 4 showed the oxidative status and antioxidant defense in chicks vaccinated against ND and treated with SILK under effect of mycotoxin reassembly by (H2O2, MDA, LPO and GSH-PX) in liver tissues, at 42 days after challenge with local isolate NDV. The third group showed a significantly decrease $(\mathrm{P}>0.05)$ in levels of oxidative enzymes followed by the (G1 and G2) groups respectively, compared to (G4 and G5) groups, which recorded a significant increase $(\mathrm{P}<0.05)$ in levels of oxidative enzymes, however a significant increase $(\mathrm{P}<0.05)$ in levels of antioxidant enzymes (GSH-PX) in G3 followed by (G1 and $\mathrm{G} 2)$ respectively, compared to (G4 and G5) groups were recorded a significant decrease at level $(\mathrm{P}>0.05)$.

Table 5 showed the oxidative status and antioxidant defense of the spleen tissue. The third group showed a significantly decrease $(\mathrm{P}>0.05)$ in levels of oxidative enzymes followed by the (G1 and G2) groups respectively, compared to (G4 and G5) groups, which recorded a significant increase $(\mathrm{P}<0.05)$ in levels of oxidative enzymes, however a significant increase $(\mathrm{P}<0.05)$ in levels of antioxidant enzymes (GSH-PX) in G3 followed by (G1 and G2) respectively, compared to (G4 and G5) groups were recorded a significant decrease at level $(\mathrm{P}>0.05)$.

Table 2: Effect of SILK on antibody titer against Newcastle disease in different periods by ELISA test

\begin{tabular}{lccccc}
\hline \multirow{2}{*}{ Periods } & \multicolumn{4}{c}{ ND antibody titre Means \pm Stander error } \\
\cline { 2 - 6 } & 14 days & 21 days & 28 days & 35 days & 42 days \\
\hline G1 & $2406.1 \pm 147.8 \mathrm{~B}$ & $3043.4 \pm 166.5 \mathrm{~B}$ & $3607.4 \pm 231.3 \mathrm{~B}$ & $4577.7 \pm 169 \mathrm{~B}$ & $6158 \pm 279.1 \mathrm{C}$ \\
G2 & $1728.6 \pm 139.1 \mathrm{C}$ & $2245.9 \pm 109.7 \mathrm{C}$ & $3039.4 \pm 73.4 \mathrm{C}$ & $3676.2 \pm 109.3 \mathrm{C}$ & $4422.4 \pm 136.4 \mathrm{D}$ \\
G3 & $3269.9 \pm 169.4 \mathrm{~A}$ & $4233.1 \pm 209.9 \mathrm{~A}$ & $5936.7 \pm 214.9 \mathrm{~A}$ & $7379.2 \pm 268.2 \mathrm{~A}$ & $9516.2 \pm 233.2 \mathrm{~B}$ \\
G4 & $890.3 \pm 41.8 \mathrm{D}$ & $1733.7 \pm 123.7 \mathrm{D}$ & $2112.2 \pm 185 \mathrm{D}$ & $2357.1 \pm 157.9 \mathrm{D}$ & $2112.2 \pm 185 \mathrm{E}$ \\
G5 & $0 \pm 0 \mathrm{E}$ & $0 \pm 0 \mathrm{E}$ & $709.4 \pm 69.9 \mathrm{E}$ & $1633.7 \pm 135.6 \mathrm{E}$ & $15792.2 \pm 903.9 \mathrm{~A}$ \\
\hline LSD & 340.77 & 400.88 & 483.46 & 518.15 & 1274.4 \\
\hline
\end{tabular}

Number of samples: 10; Different letters mean significant difference at level of (P<0.05); LSD: less significant differences.

Table 3: Effect of SILK on antibody titer against Newcastle disease in different periods by HI test

\begin{tabular}{lccccc}
\hline \multirow{2}{*}{ Periods } & \multicolumn{5}{c}{ ND antibody titer Means \pm Stander error } \\
\cline { 2 - 6 } & 14 days & 21 days & 28 days & 35 days & 42 days \\
\hline G1 & $61.2 \pm 2.9 \mathrm{~B}$ & $77.8 \pm 3.1 \mathrm{~B}$ & $93.2 \pm 4 \mathrm{~B}$ & $120.2 \pm 8.1 \mathrm{~B}$ & $158.4 \pm 9.7 \mathrm{C}$ \\
$\mathrm{G} 2$ & $43.4 \pm 3.47 \mathrm{C}$ & $58 \pm 4 \mathrm{C}$ & $78.6 \pm 3.2 \mathrm{C}$ & $93.8 \pm 2.5 \mathrm{C}$ & $114.6 \pm 5.9 \mathrm{D}$ \\
$\mathrm{G} 3$ & $83.8 \pm 3.9 \mathrm{~A}$ & $108 \pm 4.9 \mathrm{~A}$ & $155.4 \pm 9.4 \mathrm{~A}$ & $202.2 \pm 9.8 \mathrm{~A}$ & $248.6 \pm 15 \mathrm{~B}$ \\
$\mathrm{G} 4$ & $23.6 \pm 1.9 \mathrm{D}$ & $43 \pm 5 \mathrm{D}$ & $53.4 \pm 6.2 \mathrm{D}$ & $61.6 \pm 5.2 \mathrm{D}$ & $54.2 \pm 4.16 \mathrm{E}$ \\
G5 & $0 \pm 0 \mathrm{E}$ & $0 \pm 0 \mathrm{E}$ & $22.4 \pm 2.77 \mathrm{E}$ & $41.8 \pm 5.7 \mathrm{E}$ & $415.4 \pm 15.5 \mathrm{~A}$ \\
\hline LSD & 11.785 & 16.294 & 23.863 & 21.321 & 46.229 \\
\hline
\end{tabular}

Number of samples: 5; Different letters mean significant difference at level of $(\mathrm{P}<0.05)$; LSD: less significant differences. 
Table 6 showed the clinical signs and mortality in groups vaccinated against ND and treated with SILK, after challenge with virulent local isolate of NDV $\left(100 \mathrm{ELD}_{50} 10^{5}\right)$ at 25 days, there was a significant decrease $(\mathrm{P}>0.05)$ in rates of morbidity and mortality in treated groups with SILK (G3, G1 and G2) groups, while not treated groups (G5 and G4) showed a highly significant increase $(\mathrm{P}<0.05)$ in morbidity and mortality rates.

Table 4: Effect of SILK on oxidative status and antioxidant defense in liver exposed to mycotoxins

\begin{tabular}{lcccc}
\hline \multirow{2}{*}{ Periods } & \multicolumn{4}{c}{ Means \pm Stander error } \\
\cline { 2 - 5 } & $\mathrm{H}_{2} \mathrm{O}_{2}(\mathrm{mmol} / \mathrm{g}$ pro $)$ & MDA $(\mathrm{nmol} / \mathrm{g}$ pro $)$ & $\mathrm{LPO}(\mu \mathrm{mol} / \mathrm{g}$ pro $)$ & GSH-px $(\mathrm{U})$ \\
\hline $\mathrm{G} 1$ & $14.55 \pm 0.29 \mathrm{BC}$ & $2.99 \pm 0.05 \mathrm{D}$ & $1.11 \pm 0.03 \mathrm{BC}$ & $37.44 \pm 0.3 \mathrm{~A}$ \\
$\mathrm{G} 2$ & $15.75 \pm 0.26 \mathrm{~B}$ & $3.44 \pm 0.13 \mathrm{C}$ & $1.26 \pm 0.03 \mathrm{~B}$ & $34.31 \pm 0.26 \mathrm{~B}$ \\
$\mathrm{G} 3$ & $13.57 \pm 0.32 \mathrm{C}$ & $2.63 \pm 0.08 \mathrm{D}$ & $0.97 \pm 0.01 \mathrm{C}$ & $39.08 \pm 0.55 \mathrm{~A}$ \\
$\mathrm{G} 4$ & $18.28 \pm 0.38 \mathrm{~A}$ & $4.97 \pm 0.05 \mathrm{~B}$ & $2.08 \pm 0.04 \mathrm{~A}$ & $30.26 \pm 0.5 \mathrm{C}$ \\
$\mathrm{G} 5$ & $18.08 \pm 0.32 \mathrm{~A}$ & $4.26 \pm 0.13 \mathrm{~A}$ & $1.84 \pm 0.11 \mathrm{~A}$ & $32.04 \pm 0.38 \mathrm{C}$ \\
\hline LSD & 1.33 & 0.41 & 0.24 & 1.79 \\
\hline
\end{tabular}

Number of samples: 5. Different letters mean significant difference at level of ( $\mathrm{P}<0.05)$; GSH-Px: glutathione peroxidase; MDA: malondialdehyde; H2O2: hydrogen peroxide; LPO: lipid peroxidation. LSD: less significant differences.

Table 5 Effect of SILK on oxidative status and antioxidant defense in spleen exposed to mycotoxins

\begin{tabular}{lcccc}
\hline \multirow{2}{*}{ Periods } & \multicolumn{4}{c}{ Means \pm Stander error } \\
\cline { 2 - 5 } & $\mathrm{H}_{2} \mathrm{O}_{2}(\mathrm{mmol} / \mathrm{g}$ pro $)$ & MDA $(\mathrm{nmol} / \mathrm{g}$ pro $)$ & LPO $(\mu \mathrm{mol} / \mathrm{g}$ pro $)$ & GSH-px $(\mathrm{U})$ \\
\hline $\mathrm{G} 1$ & $15.35 \pm 0.27 \mathrm{BC}$ & $2.19 \pm 0.22 \mathrm{BC}$ & $4.06 \pm 0.04 \mathrm{BC}$ & $42.31 \pm 0.37 \mathrm{~B}$ \\
$\mathrm{G} 2$ & $16.15 \pm 0.27 \mathrm{~B}$ & $2.64 \pm 0.31 \mathrm{BC}$ & $4.88 \pm 0.16 \mathrm{AB}$ & $41.22 \pm 0.51 \mathrm{~B}$ \\
$\mathrm{G} 3$ & $14.37 \pm 0.22 \mathrm{C}$ & $1.83 \pm 0.16 \mathrm{C}$ & $3.77 \pm 0.13 \mathrm{C}$ & $44.48 \pm 0.5 \mathrm{~A}$ \\
$\mathrm{G} 4$ & $19.28 \pm 0.35 \mathrm{~A}$ & $3.97 \pm 0.32 \mathrm{~A}$ & $5.31 \pm 0.14 \mathrm{~A}$ & $37.06 \pm 0.39 \mathrm{C}$ \\
$\mathrm{G} 5$ & $18.68 \pm 0.34 \mathrm{~A}$ & $3.26 \pm 0.29 \mathrm{AB}$ & $5.11 \pm 0.36 \mathrm{~A}$ & $38.66 \pm 0.48 \mathrm{C}$ \\
\hline LSD & 1.24 & 1.13 & 0.84 & 1.91 \\
\hline
\end{tabular}

Number of samples: 5. Different letters mean significant difference at level of (P<0.05); GSH-Px: glutathione peroxidase; MDA: malondialdehyde; H2O2: hydrogen peroxide; LPO: lipid peroxidation. LSD: less significant differences.

Table 6: The morbidity and mortalities through 10 days after challenge with local NDV isolate at 25 days

\begin{tabular}{lcc}
\hline \multirow{2}{*}{ Periods } & \multicolumn{2}{c}{ Means \pm Stander error } \\
\cline { 2 - 3 } & Morbidity \% & Mortality $\%$ \\
\hline G1 & $40 \%(8) \mathrm{d}$ & $10 \%(2) \mathrm{d}$ \\
G2 & $60 \%(12) \mathrm{c}$ & $25 \%(5) \mathrm{c}$ \\
G3 & $25 \%(5) \mathrm{e}$ & $0 \%(0) \mathrm{d}$ \\
G4 & $80 \%(16) \mathrm{b}$ & $55 \%(11) \mathrm{b}$ \\
G5 & $100 \%(20) \mathrm{a}$ & $100 \%(20) \mathrm{a}$ \\
\hline
\end{tabular}

Number of chicks for each group: 20. Different letters mean significant difference at level of $(\mathrm{P}<0.05)$.

\section{Discussion}

The results of the present study showed a significant increase in the Abs against ND in G3 compared with other groups, this return to the role of SILK enhancing the immune response after vaccination with live vaccines through drinking water in the first periods of chick life, also increasing response after oil vaccination these results agree with (15), whom demonstrated the role of SILK in increasing the cytokines which are natural stimulators and mediators of immune cells towards infectious organism thus increasing special Abs against antigens (Ag) and have an effective and influential role in stimulating and differentiation of immune cells in natural and acquired immunity. Rashad and Mushtaq, (10), demonstrated the role of SILK in protection the chicks from ND infection after challenge with virulent local isolate of ND in the first day. Immune response in G1 was better than G2 the results were consistent with (10), who demonstrated that the immunogenicity of the live vaccine was a cellular immunity primarily dependent on Cytokines and its role in stimulating many defense cells against infectious antigens, While the vaccination with killed vaccines stimulating Humoral immunity, which relies on the stimulation of $\mathrm{B}$ cells that produce $\mathrm{Ab}$ according to amount of $\mathrm{Ag}$ in the killed vaccine without reliance on other defense cells, which explains the slow immunity available from the killed vaccines. The reason of increase in immune response in G5 after challenge virulent local isolate of $\mathrm{ND}$, return to not vaccinated against ND to protect the chicks from infection, These results agreed with (16), who proved that the chicks were exposed to NDV infection in the third week 
after decline the maternal immunity and highly increase of Abs with high mortality in chicks due to acute infection. But the low Ab titre in G4 return to toxic effect of mycotoxin these results agree with (4) show that mycotoxins damage the proteins found in cell junctions and thus reduce the transmission of electrical impulses, that transfer of cytokines between immune cells. Also metabolic products of innate toxins affect the immune system of the intestinal mucous, which in turn significantly affects the performance and productivity of the animal, because the stimulation of mucous immunity is important in protecting against many of the antigens that invade these surfaces and enter the body and cause diseases (5).

G3 show significant decrease in oxidative status like ( $\mathrm{H} 2 \mathrm{O} 2$, MDA and LPO) in hepatic and splenic tissues at 42 days after challenge with virulent local isolate of ND at 25 days, return to role of SILK in enhancement the immune response against NDV by protected the hepatic and splenic cell from infection with NDV these results agree with (17), whom demonstrated the role of acquired immunity from live vaccines in stimulated the immune cells forwards to antigens by increasing the cytokines thus prevented the Ags to damage the vital organs like (liver and spleen). Also agree with results of (18), whom proved decrease in oxidative status and increase in antioxidant defense in bird vaccinated with live vaccines of ND and challenge with virulent local isolate of ND. While G5 which showed opposite results because birds were not vaccinated and not protected against NDV these results go in the line with (16). A Group 4 shows opposite results because of the toxic mycotoxins effects which have been closely associated with ROS generation mainly include hydroxyl (OH-), $\mathrm{O} 2$ and hydrogen peroxide (19). Excessive increase of ROS promotes lipid peroxidation, which inhibits membrane functions by reducing membrane solubility and large changes in all enzymes and membrane receptors (20). In addition, MDA is formed at the end of fat peroxide and reflects the final grade of lipid oxidation in the body. Free radicals and lipid peroxides are controlled by the antioxidant defense system, which contains enzymatic compounds such as GR and GSHPX (21).

Group 5 which showed opposite results because birds were not vaccinated and not protected against NDV and these results went with (16). Also Group 4 shows opposite results Due to the mycotoxins toxic effects, which is in agreement with (10).

\section{Conclusion}

From all above-mentioned results, it could be concluded that SILK before vaccination helps protect the chicks from infection with NDV by enhancement and stimulate the immune cells, also make them ready to defend against any ages.

\section{Acknowledgments}

We offer our greetings and blessings to the College of Veterinary Medicine, University of Baghdad for its provision of all research requirements, as well as we thank all those who supported us in any field during the completion of the project.

\section{Conflict of interest}

There is no difference or contradiction with the scientific and practical interest, but rather the attribution of scientific reality with new scientific efforts and ideas.

\section{References}

1. Yiannikouris A, Jonany J. Mycotoxins in feeds and their fate in animals: a review. Anim Res. 2002;51:81-99. DOI: 10.1051/animres:2002012.

2. Prelusky, D.B., Trenholm, H.L., Rotter, B.A., Miller, J.D., Savard, M.E., Yeung,J.M. and Scott, P.M. (). Biological fate of fumonisin B1 in food-producing animals. Advances in Experimental Medicin and Biology, 1996:392, 265 - 278. DOI: 10.1007/978-1-4899-1379-1_23.

3. Bouhet S, Oswald IP. The effects of mycotoxins, fungal food contaminants, on the intestinal epithelial cell-derived innate immune response. Vet Immunol Immunopathol. 2005;108:199-209. DOI: 10.1016/j.vetimm.2005.08.010.

4. McLaughlin J., Padfield P. J., Burt J. P. H. and O'Neill C. A. Ochratoxin A increases permeability through tight junctions by removal of specific claudin isoforms. Am J Physiol Cell Physiol. 2004; 287:1412-1417. https://doi.org/10.1152/ajpcell.00007.2004

5. Streatfield SJ. Mucosal immunization using recombinant plant-based oral vaccines. Methods. 2006; 38:150-157. DOI: 10.1016/j.ymeth.2005.09.013.

6. Gertner L. R. S., Santin E.and Saad M. B. Influência da fumonisina sobre a resposta imunológica de aves: revisão bibliográfica. Revista Acadêmica: Ciências Agrárias e Ambientais. 2008; 6: 401-411. doi:10.7537/marsrsj110419.08.

7. Mayo MA. A summary of the changes recently approved by ICTV. Arch Virol. 2002;147:1655-1656. https://doi.org/10.1007/s007050200039.

8. Alexander DJ, Senne DA. Newcastle disease, other avian paramyxoviruses, and pneumovirus infections In: Saif YM, Fadly AM, Glisson JR, McDougald LR, Nolan LK, Swayne DE editors. Diseases of poultry. $12^{\text {th }}$ ed. Iowa: Black Well publishing; 2008. 75-100 p. DOI: 10.20506/rst.19.2.1231.

9. Mushtaq TB, Waleed HH. Hepatoprotective and immunostimulatory effect of ganoderma, andrographolide and turmeric against aflatoxicosis in broile chickens. Inter J Poult Sci. 2017; (1682-8356): 281. DOI: 10.3923/ijps.

10. Rashad AM, Mushtaq TB. Protection of neonatal broiler by using T cell lymphokines prepared from immunization with Salmonella typhimurium against field local newcastle disease virus isolate. Inter $\mathbf{J}$ Poult Sci. 2018; (1682-8356): 367.373. DOI: 10.3923/ijps.

11. Mushtaq TB, Sahar DA, Sahar HA, Ihsan MS. Using $T$ cell lymphokines of hyperimmunized chickens with Salmonella enteritidis to protect neonatal broiler chicks against infectious bronchitis disease. Inter J Poult Sci. 2018; (1682-8356) :493.498. DOI: 10.3923/ijps.

12. Mushtaq TB. Using prophylactic salmonella immune lymphokines to resist the avian influenza in broiler chickens Inter J Poult Sci. 2018; (1682-8356): 467.472. DOI: 10.3923/ijps.

13. Reed LJ, Muench H. A simple method of estimating fifty per cent endpoints. Am J Hyg. 1938; 27,493-497. https://doi.org/10.1093/oxfordjournals.aje.a118408 
14. OIE. Newcastle disease, in: OIE terrestrial manual: manual of diagnostic tests and vaccines for terrestrial animals. World Organisation for Animal Health. Paris. France 2012; Seventh Edition: (97892):9044-878-5. http://www.oie.int

15. Alfaro JC, Petrone VM, Fehervari T, Nava G, Kogut M, Nisbet D, Tellez G. Resistance to velogenic Newcastle disease virus in leghorn chickens by use of prophylactic lymphokines. Avi Dis. 2002; 46:525534. DOI: 10.1637/0005-2086(2002)046[0525: RTVNDV] 2.0.CO; 2.

16. Mushtaq TB, Sahar HA, Raed HS, Amer AA. Isolation and identification of the Newcastle disease virus from field outbreaks in broiler and layer flocks in Iraq. Iraqi J Vet Med. 2017; 41 (1): 23-27. DOI: https://doi.org/10.30539/iraqijvm.v41i1.73.

17. Kaiser MG, Cheeseman JH, Kaiser P, Lamont SJ. Cytokine expression in chicken peripheral blood mononuclear cells after in vitro exposure to Salmonella enterica serovar Enteritidis. Poult Sci. 2006; 85:1907-1911. DOI: $10.1093 / \mathrm{ps} / 85.11 .1907$.
18. Kapczynski DR, Afonso CL, Miller PJ. Immune responses of poultry to Newcastle disease virus. Dev Comp Immunol. 2013; 41:447-453. DOI: 10.1016/j.dci.2013.04.012.

19. Mehrzad J, Klein G, Kamphues J, Wolf P, Grabowski N, Schuberth HJ. In vitro effects of very low levels of aflatoxin B1 on free radicals' production and bactericidal activity of bovine blood neutrophils. Vet Immunol Immunopathol. 2011; 141:16-25. DOI: 10.1016/j.vetimm.2011.01.010.

20. Arulselvan P, Subramanian SP. Beneficial effects of Murraya koenigii leaves on antioxidant defense system and ultrastructural changes of pancreatic b-cells in experimental diabetes in rats. Chem Biol Interact. 2007; 165:155-164. DOI: 10.1016/j.cbi.2006.10.014.

21. Delles RM, Xiong YL, Ture AD, Ao T. Dawson KA. Dietary antioxidant supplementation enhances lipid and protein oxidative stability of chicken broiler meat through promotion of antioxidant enzyme activity. Poult Sci. 2014; 93:1561-1570. DOI: $10.3382 /$ ps.2013-03682. 